ISSN: $1676-6288$

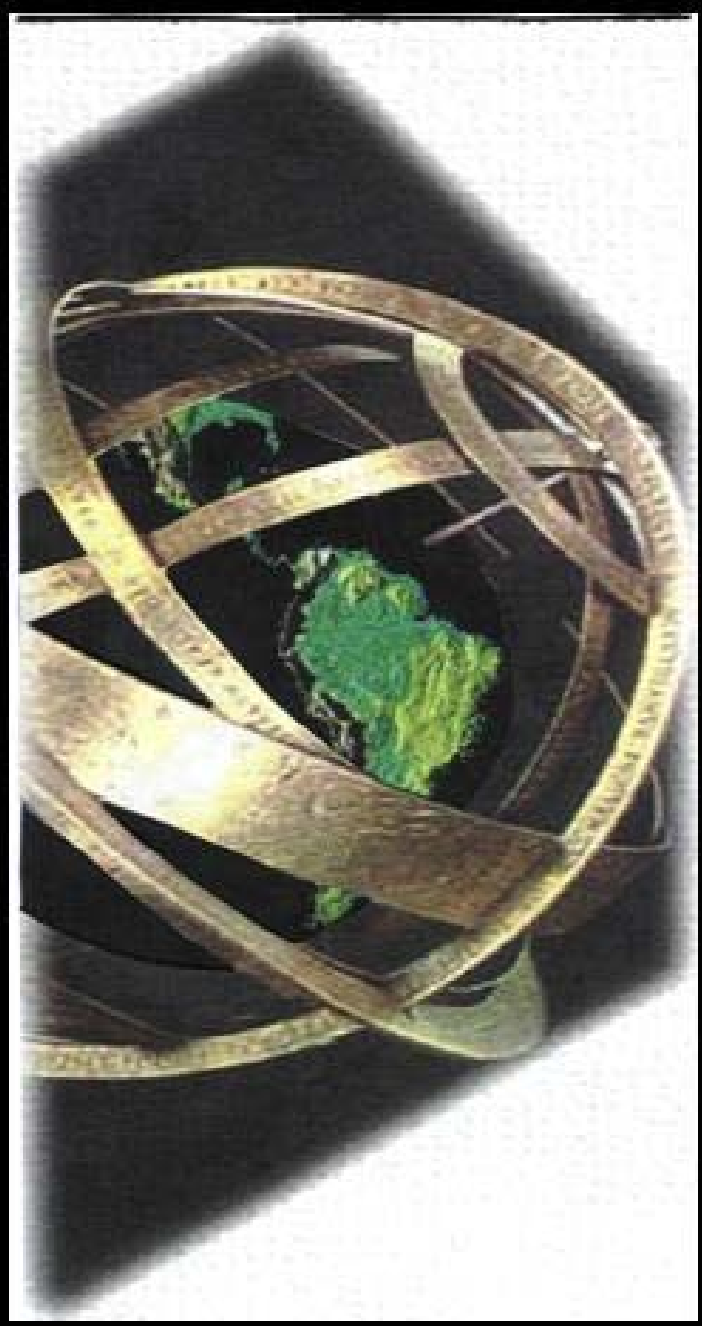

Ano 2 - V. $02-N .2-2003$
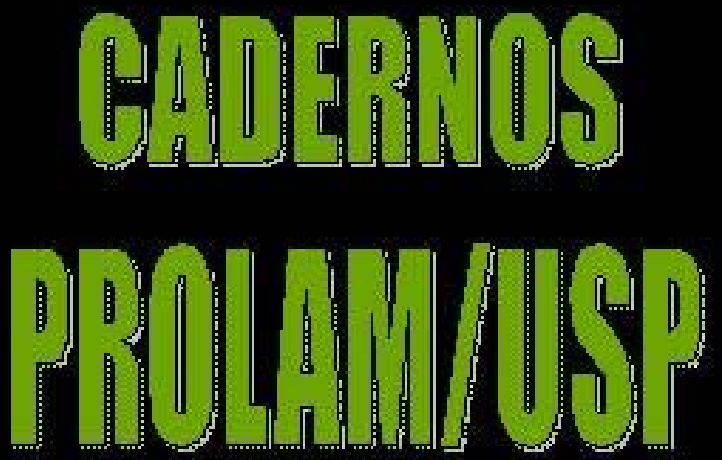

Mais Informalidade, Menos Cidadania. Os Efeitos Criados por esse Circulo Vicioso sobre a Formulação da Politica Social na América Latina

Maria Cristina Cacciamali Maria de Fátima José-Silva 


\section{PROLAM

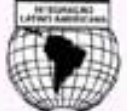 \\ CADERNOS \\ PROLAM/USP}

\section{PROGRAMA DE PÓS-GRADUAÇÃO EM INTEGRAÇÃO DA AMÉRICA LATINA DA UNIVERSIDADE DE SÃO PAULO}

\section{TSP Universidade de Săo Paulo}

Reitor: Prof. Dr. Adolpho José Melfi

Vice-Reitor: Prof. Dr. Hélio Nogueira da Cruz

Pró-Reitora de Pós-Graduação: Profa. Dra. Suely Vilela

Pró-Reitor de Cultura e Extensão Universitária: Prof. Dr. Adilson Avansi de Abreu

Pró-Reitor de Pesquisa: Prof. Dr. Luiz Nunes de Oliveira

Pró-Reitora de Graduação: Profa. Dra. Sonia Teresinha de Sousa Penin

Presidente do PROLAM/USP: Profa. Dra. Maria Cristina Cacciamali

Vice-Presidente do PROLAM/USP: Profa. Dra. Cremilda Medina

Comissão de Pós-Graduação do PROLAM/USP:

Presidente: Profa. Dra. Maria Cristina Cacciamali

Vice-Presidente: Profa. Dra. Cremilda Medina

Prof. Dr. Afrânio Mendes Catani

Profa. Dra. Maria Lúcia Refinetti Martins

Prof. Dr. Osvaldo Luis Angel Cogiolla

Prof. Dr. Paulo Borba Casella

Representante Discente: Lúcia Elena Arantes Ferreira

\section{CONSELHO EDITORIAL}

Presidente do Conselho Editorial: Prof. Dr. Sedi Hirano (FFLCH/PROLAM/USP)

E-mail: sedihi@usp.br

\section{MEMBROS DO CONSELHO EDITORIAL}

Adalberto Santana (UNAM/ México)

Afrânio Mendes Catani (FE/USP)

Amália Inês Geraiges de Lemos (FFLCH/USP)

Aníbal Quijano (CEIS/Peru)

Anita Kon (PUC/SP)

Carlos Antonio Romero Méndez (UCV/Venezuela)

Catalina Banko (UCV/ Venezuela)

Cremilda Celeste de Araújo Medina (ECA/USP)

Dilma de Melo Silva (ECA/USP)

Gustavo Arce (RAU/Uruguai)

Irlemar Chiampi (FFLCH/USP)

José Augusto Guilhom Albuquerque (FFLCH/USP)

Juan Carlos Campbell Esquivel (UCV/Chile)

Lisbeth Rebollo Golçalves (ECA/USP)

Lúcia Emília Nuevo Barreto Bruno (FE/USP)

Editora: Profa. Dra. Maria Cristina Cacciamali

E-mail: cciamali@uol.com.br
Luis Felipe Cabrales Barajas (UCSHUG/México) Luís Maurício Cuervo (UNIANDES/Colômbia)

Maria Cristina Cacciamali (FEA/USP)

Maria Lúcia Refinetti Martins (FAU/USP)

Márcio Bobik Braga (FEA/USP)

Margarida Maria Krohling Künsch (ECA/USP)

Osvaldo Luis Angel Coggiola (FFLCH/USP)

Paulo Borba Casella (FD/USP)

Rafael Campos Sanchez (UNAM/México)

Raúl Bernal-Meza (UNCPBA/Argentina)

Renato da Silva Queiroz (FFLCH/USP)

Ricardo Antunes (IFCH/UNICAMP)

Sandra Maria Zakia Lian Sousa (FE/USP)

Sedi Hirano (FFLCH/USP)

Sueli Teresina Ramos Schiffer (FAU/USP)

Secretária Editorial: Marizete Liamar Grando

E-mail:prolamev@edu.usp.br 


\section{OBJETIVOS}

O Cadernos PROLAM/USP é uma publicação periódica bimestral, indexada, com Conselho Editorial de Arbitragem. O eixo temático é a integração da América Latina analisado sob quaisquer das seguintes dimensões: social, econômica, política, relações internacionais e cultural.

Todos os trabalhos são submetidos ao Conselho Editorial e avaliados por pareceristas, não havendo identificação do(s) autor(es). 


\section{NORMAS EDITORIAIS}

Cada número do CADERNOS PROLAM/USP será composto por um ensaio ou conjunto de artigos, contendo no máximo 50 páginas. O padrão é: letra Times New Roman; espaço 1,5; notas colocadas no rodapé de cada página; simples referência de autoria colocada entre parênteses no próprio texto; referências da bibliografia efetivamente citada ao longo do artigo listadas no final do texto, de acordo com a norma NBR-6023 da ABNT Internacional; o autor deverá fornecer disquete do texto em WORD 6.0. RTF em arquivo próprio; o autor deverá fornecer disquete das tabelas e gráficos em EXCEL. RTF em arquivo próprio; mapas deverão ser entregues nos formatos originais e separados do texto. Os idiomas da publicação serão: português, espanhol, inglês ou francês. 


\title{
Mais Informalidade, Menos Cidadania. Os Efeitos Criados por esse Círculo Vicioso sobre a Formulação da Política Social na América Latina ${ }^{1}$
}

\author{
Maria Cristina Cacciamali ${ }^{2}$ \\ Maria de Fátima José-Silva ${ }^{3}$
}

\begin{abstract}
Resumo
O texto analisa o processo de informalidade e suas relações com a construção da cidadania na América Latina nas duas últimas décadas. Para isso, a primeira parte discute o conceito de cidadania, apresenta o contexto macroeconômico e político e analisa o processo de informalidade que foi engendrado por esse novo ambiente, o qual destrói e adapta as regras de contratação do mercado de trabalho, permitindo maior evasão do sistema de seguridade social em quaisquer formas de inserção laboral. A segunda parte centra-se no setor informal - microempresas e trabalhadores por conta própria - que operam em geral à margem da legislação trabalhista, criando valores antagônicos à construção de uma cidadania ativa. Para concluir, o texto alerta para os problemas que o trabalho informal pode acarretar para o desenvolvimento político e social de um país, e para os graves problemas que, a partir dele podem advir, como por exemplo, o retorno do populismo.
\end{abstract}

Palavras-chave: processo de informalidade, setor informal, políticas públicas, cidadania.

\section{Resumen}

El texto analiza el proceso de informalidad y sus relaciones con la construcción de la ciudadanía en América Latina en las últimas décadas. Para eso, la primera parte discute el concepto de ciudadanía, presenta el contexto macroeconómico y político e analiza el proceso de informalidad engendrado por ese nuevo ambiente, que destruye y readapta las reglas de contratación del mercado de trabajo, permitiendo una mayor evasión al sistema de seguridad social en cualquiera de sus formas de inserción laboral. La segunda parte se centra en el sector informal micro-empresas e trabajadores por cuenta propia - que opera en general al margen de la legislación laboral, creando valores antagónicos a la construcción de una ciudadanía activa. Para concluir el texto alerta de los problemas que el trabajo informal produce frente al desarrollo político y social de un país, y para los graves problemas que pueden advertirse, como por ejemplo, el retorno del populismo.

Palabras-clave: proceso de informalidad, sector informal, políticas públicas, ciudadanía.

\footnotetext{
${ }^{1}$ As autoras agradecem os comentários do Prof. Dr. Jaime Marques Pereira (IHEAL).

2 Doutora e Livre-Docente pela Universidade de São Paulo com Pós-Doutorado pelo Massachusetts Institute of Technology. Atualmente é Professora Titular do Departamento de Economia e Presidente do Programa de Pós-Graduação em Integração da América Latina da mesma Universidade onde leciona e pesquisa na área de Estudos do Trabalho. Bolsista CNPq. E-mail: cciamali@uol.com.br.

3 Doutoranda do Programa de Pós-Graduação em Integração da América Latina (PROLAM) da Universidade de São Paulo, atualmente é professora da Universidade Federal de São Paulo UNIFESP/EPM e pesquisadora nas áreas de Psicologia Social e Hospitalar. E-mail: fatimajs@uol.com.br
} 


\section{Introdução}

As mudanças estruturais e culturais contemporâneas levam à necessidade de distinguir este momento do capitalismo com momentos anteriores (HOBSBAWM, 1995), especialmente com relação à Idade de Ouro, compreendida pelo período entre o fim da segunda guerra mundial até o final dos anos 60. Para os propósitos deste artigo, destacamos dois aspectos distintivos do processo de mundialização ${ }^{4}$, sem a pretensão de exaurirmos as diferenças.

O primeiro emerge do campo econômico, embora sua raiz esteja cravada numa opção política. Refere-se ao predomínio da atividade financeira e ao manejo da política econômica que dela decorre: restringe a soberania das nações, e redefine não apenas a política monetária, mas igualmente a política econômica e social, com efeitos na distribuição funcional de renda. Um dos subprodutos deste quadro é que, o ajustamento macroeconômico na América Latina e, portanto, o crescimento econômico, vem ocorrendo por meio de forte instabilidade, em virtude da maior dependência externa, seja pelo fluxo de capitais especulativos, pelo endividamento público ou ainda pelo insuficiente volume das exportações. O mercado de trabalho reflete os efeitos perversos dessa opção política, expressados pelas maiores taxas de desemprego, de longa e curta duração, pela insegurança nas relações de trabalho, pelo rebaixamento salarial e pelo processo de informalidade.

A segunda distinção encontra sua base no desgaste da regulação do mercado de trabalho, base da sociedade salarial (CASTEL, 1998). Esta mutação torna-se mais intensa nos anos de 1990, pois deriva substancialmente das mudanças nos rumos da política monetária, como também das restrições para o financiamento das políticas de bem estar social. Esse último ponto é vital ao tema que estamos tratando, posto que, está associado ao processo de rompimento entre trabalho e cidadania, caso seja adotada a definição na qual o primeiro é o emprego típico assalariado, com contrato por tempo indeterminado. Devemos lembrar que, na América Latina, expressiva parte dos direitos sociais, na sua origem, na década de 1930, foi manifesta pelo Estado, justamente para regrar a relação assalariada do setor privado. Posteriormente, na década

\footnotetext{
${ }^{4}$ A denominação processo de mundialização neste trabalho refere-se aos processos de ajustamento das economias nacionais ao estado das relações internacionais, sob hegemonia norte-americana, e à
} 
de 1980, os direitos sociais foram ampliados para aquelas pessoas que exerciam seu trabalho sob essa forma, ou seja, no setor privado através de uma relação assalariada regular, por tempo indeterminado e em período integral. Diferentemente, por exemplo, da construção da legislação social da sociedade assalariada na França, que, em sua gênese, traduziu a prática da classe empresarial, na seqüência, veio a responder às demandas sociais do operariado e, por fim, àquelas das classes médias (CASTEL, 1998). As reformas das legislações trabalhistas ocorridas nos países latino-americanos, especialmente na década e 1990, ou o desgaste da legislação vigente, como no caso brasileiro, compuseram e reforçaram a política macroeconômica dos governos, o que repercutiu sobre o mercado de trabalho, por meio de um maior número de contratações de assalariados sem registro, no alargamento do trabalho por conta própria, e na extensão da ocupação nos pequenos negócios e no comércio de rua (CACCIAMALI, 1999).

Os dois aspectos distintivos apontados acima - de um lado, financerização e política macroeconômica; e de outro, reformas ou desgaste da legislação trabalhista - conduzem à extensão, diferenciação e ao aprofundamento dos processos de informalidade na região latinoamericana, que por sua vez intensificam a contradição com a necessidade de ampliar e compor a cidadania. A importância dos poderes públicos repousa principalmente na ação emancipadora da cidadania e não no exercício punitivo ou nas ações assistencialistas para aqueles que se encontram à margem da formalidade (ABREU, 1987; COSTA, 1989).

Cidadania pressupõe uma série de direitos, deveres, atitudes relativas aos cidadãos. Cidadania é, portanto, qualquer atitude cotidiana, individual ou coletiva, que implique compromisso social, consciência de pertinência e de responsabilidade.

Em diversos períodos históricos os conceitos sobre a cidadania tiveram seu palco. Sabemos que:

“a palavra cidadania foi usada na Roma antiga para indicar a situação política de uma pessoa e os direitos que essa pessoa tinha ou podia exercer. A sociedade romana fazia discriminação e separava as pessoas em classes sociais (...) com o tempo foram criadas categorias intermediárias, para que plebeus recebessem um título mais próximo dos 
patrícios. Os romanos livres tinham cidadania e já faziam distinção entre cidadania e cidadania ativa" (DALLARI,1998:10).

Durante o renascimento europeu retomam-se os conceitos de cidadania, identifica-se que se valeram do exemplo da cidadania romana, enfatizando a autodisciplina, o patriotismo e a preocupação com o bem comum, no que diz respeito à relação entre direitos e deveres dos cidadãos. Prosseguindo, chegaremos aos burgos da Europa medieval e às cidades do Renascimento. A Europa, nos séculos XVII e XVIII, dava início aos tempos modernos, registrase que, nesse período, os nobres gozavam de privilégios, estavam isentos ou sonegavam impostos, eram grandes proprietários de terra e ocupavam os mais importantes cargos políticos. Nessa fase, os reis eram os governantes e tinham em mãos poderes absolutos.

No ano de 1789, após a Revolução Gloriosa, ocorre na França um movimento revolucionário - Revolução Francesa -, nasce, naquele momento, a moderna concepção de cidadania, a qual se constitui em um marco nas lutas sociais, na eliminação de privilégios. Inicia-se, a partir de então, a construção de uma nova organização social e de um novo sistema de governo. Porém, como todo processo de mudança engendra resistências, dois anos após iniciado o movimento, em 1791, reunidos em assembléia, os líderes da Revolução Francesa introduzem novas regras, nas quais se define que, para ser um cidadão ativo era preciso ser francês, do sexo masculino, proprietário de bens e imóveis e registrar anualmente uma renda mínima elevada. A instalação dessas novas regras, porém, deformou completamente a idéia original que se concedeu à cidadania.

A moderna concepção de cidadania julgava:

“ (...) possui um caráter próprio. Primeiro, a cidadania formal é hoje quase universalmente definida como a condição de membro de um estado-nação. Em segundo lugar, porém, a cidadania substantiva, definida como a posse de um corpo de civis (leis), políticos e especialmente sociais, tem-se tornado cada vez mais importante. 
Em ambos esses aspectos, houve um processo de desenvolvimento durante o século XX, e mais marcadamente a partir da Segunda Guerra Mundial, que coloca algumas questões novas. A cidadania formal tornou-se uma questão mais importante, em conseqüência da maciça imigração, no pós-guerra, para a Europa Ocidental e a América do Norte, o que resultou numa nova política de cidadania". (BRUBAKER,1992, Apud BOTTOMORE,1996:73-74).

Em 1950, Marshall analisa e descreve a cidadania substantiva, como sendo um processo de extensão de direitos civis, políticos e sociais, existentes para toda a população de uma nação. Na Europa Ocidental, após 1945, registra-se o aumento dos direitos sociais - a criação do ESTADO DE BEM-ESTAR - que no seu bojo estabeleceu princípios mais igualitários, coletivistas e políticas que, em certa medida, serviram de equilíbrio às tendências não igualitárias da economia capitalista (BOTTOMORE,1996).

Podemos pensar na concepção de cidadania, transformada, conscientizada e interiorizada na idéia de maior participação popular nos negócios do governo, não apenas de uma comunidade nacional, mas também de associações regionais mais amplas, como a União Européia, Mercosul, entre outros. Contudo, a participação ativa pressupõe progressivos aumentos dos direitos sociais.

Estamos vivendo, na América Latina, processos de aprofundamento da democracia, onde a palavra-chave é cidadania, porém este termo é utilizado, inúmeras vezes, de forma controvertida ou equivocada, inclusive pela ausência de debates públicos que discutam o seu conceito e os limites que este pode impor à ação política. Muitas vezes o uso da palavra não compreende sequer o conceito jurídico strictu sensu. Ou seja, cidadão é o indivíduo vinculado á ordem jurídica do Estado, que por sua vez:

"é membro de uma comunidade nacional, no gozo dos direitos individuais e coletivos - políticos sociais, econômicos - , assegurados 
pela Constituição e/ou pelas leis do seu país e sujeito às obrigações e limitações impostas por elas" (FARHAT, 1996: 119).

Por outros fatores, que não cabem nos limites deste artigo, não há consenso com relação aos desdobramentos e sobre a abrangência desse termo. Dentre as dimensões que encerram forte subjetividade, a partir de diferentes correntes de pensamento, análises e decantações, destacamos o equilíbrio entre o público e o privado, a contradição entre os conceito de civismo e civil, valores religiosos, laicos e republicanos e os sentimentos de pertencimento e de engajamento. (VIEIRA, 1997).

Mediante a constatação dessas dificuldades, a trajetória da construção da cidadania na América Latina, vem acompanhada de grandes desafios e de uma árdua caminhada. Contextualizando, não podemos esquecer que durante as duas últimas décadas, a sociedade latino-americana teve como cenário: a transição democrática, marcada pelos desequilíbrios econômicos - década perdida -; instabilidade e violação dos direitos individuais, coletivos e sociais; desregulamentação da economia, liberalização comercial e reestruturação produtiva selvagem, o que levou a maior parte dos países de região a mundializarem-se de forma submissa, subserviente, subterrânea e sem parâmetros de legalidade. Podemos, assim dizer, que estes são alguns dos dilemas contemporâneos latino-americanos.

Discutiremos na próxima sessão o processo de informalidade, a partir do processo de mundialização e, na seqüência, trataremos de algumas relações entre informalidade e cidadania. Por fim, serão tecidas as considerações finais.

\section{Processo de Informalidade}

O ajustamento do mercado de trabalho latino americano, após os anos $80 \mathrm{e}$, especialmente nos anos 90, mostrou a amplificação do setor informal. Sobre isso a CEPAL indica que: 
“de cada 100 empregos gerados durante 1990-1995, 84 correspondem ao setor informal. De cerca de 16 milhões de empregos criados na América Latina (...) no período de 1990-1994, cerca de 14,4 milhões corresponderam ao dito setor, que agrupou assim, 56\% do total dos ocupados da região, (incluídos os que trabalham no serviço doméstico). O setor informal mais dinâmico é das microempresas $(52 \%$ do crescimento a anual para 1990-1995), setor que hoje representa 22,5\% do emprego total da região, frente a 20,2\% em 1990. Os trabalhadores informais por conta própria também aumentaram $\left(\begin{array}{lll}44 \% & \text { aa }\end{array}\right)$ e representam agora $26,5 \%$ do total de ocupados na região, quase dois pontos percentuais a mais que em 1990. A ocupação no serviço doméstico aumentou em 3,9\%aa, empregando-se aqui 7,1\% (em 1996) do total dos ocupados frente aos 6,7\% de 1990”. (CEPAL, 1997: 65).

Os efeitos do processo de informalidade ${ }^{5}$ incidem de maneira expressiva nos mercados de trabalho da América Latina, seja sobre a forma de contratação de mão-de-obra sem registro

\footnotetext{
${ }^{5}$ Estabelece-se neste ponto um conjunto de definições. Definimos setor informal de acordo com a Organização Internacional do Trabalho, esse conceito é adotado pela maioria dos Sistemas Nacionais de Estatísticas do Trabalho e é estabelecido a partir da forma de organização das unidades produtivas. Considera-se, portanto o setor informal como o conjunto das empresas familiares operadas pelos proprietários e seus familiares, ou em sociedade com outros indivíduos. São unidades produtivas que não são constituídas como entidades legais separadas de seus proprietários e que não dispõem de registros contábeis padrão. Mercado de trabalho informal é definido como lócus de compra e venda de serviços de mão-de-obra sem registro em carteira de trabalho, ou seja, sem vínculo com a seguridade social pública. Trabalho informal é definido como qualquer forma de trabalho exercido, sem haver contribuição à seguridade social pública. E, finalmente Processo de Informalidade é conceituado como o processo de mudanças institucionais que deriva das transformações estruturais na produção e no emprego, que são impulsionadas pela liberalização do comércio, pela maior integração das economias à economia mundial e pela revolução tecnológica em andamento. $\mathrm{Na}$ dimensão do mercado de trabalho, o processo de informalidade se revela por meio da destruição, adaptação e redefinição de um conjunto de instituições, normas e regras - estabelecidas juridicamente ou por meio de práticas consuetudinárias, envolvendo os seguintes aspectos: as relações entre as empresas para organizar a produção e sua distribuição; os processos de produção e de trabalho; as formas de inserção de trabalho; as relações de trabalho; e os conteúdos das ocupações. Essas alterações se mostram e possuem um duplo efeito. De um lado, são os processos de corrosão de determinadas práticas ou instituições que se tornam inadequadas pela perda de sua eficácia e/ou de sua legitimidade política ou por envolver custos diretos ou indiretos elevado. Por outro lado, constituem os processos que definem
} 
ou no exercício do trabalhador por conta própria, nos pequenos estabelecimentos de bens e serviços ou no comércio de rua. No primeiro caso, burla-se a legislação laboral, enquanto nos demais, o exercício do trabalho ou a atividade não se encontram registrados nos órgãos competentes, em diferentes níveis do poder público (seja o fazendário, de saúde, do trabalho, de uso do espaço, entre outros).

No entanto, o traço comum entre esses dois fenômenos é que leis, normas e padrões públicos - que representam valores e que deveriam constituirem-se em parâmetros para o comportamento coletivo - não são cumpridos. Os efeitos do processo de informalidade, entretanto, espraiam-se em outras dimensões da esfera econômica, além dos mercados de trabalho e de bens, bem como se imbricam na construção de múltiplas faces da sociedade, tais como o tráfico de drogas, a prostituição, o tráfico de seres humanos, a corrupção, entre outros.

A transgressão de normas, especialmente no que se reporta ao campo fiscal, é uma prática que interpenetra as diferentes formas de organização da produção e de grupos sociais. Fatos freqüentemente veiculados pela mídia mostram que o montante devido pelos maiores devedores fiscais superaria, muitas vezes, as contribuições devidas pelos pequenos negócios ou pelos trabalhadores por conta própria. As grandes empresas possuem estratégias de elisão fiscal que, embora legalmente construídas, podem ser contestadas do ponto de vista da ética pública. Ademais, contrabando, super-faturamento de importações e sub-faturamento de exportações são expedientes freqüentemente denunciados por meio das mídias. Logo, essas práticas impõem prejuízos à receita e às políticas públicas, além de projetarem valores contrários ao bem público e à solidariedade social.

A regulamentação no uso do trabalho tem influência direta no perfil de longo prazo da distribuição funcional de renda, no cotidiano, na vida familiar e no padrão psicológico dos indivíduos, além de representar um componente importante da cidadania. Os assalariados contratados, sem registro, não têm acesso a um conjunto de garantias sociais e não compõem um corpo coletivo, por isso, não têm direitos ou obrigações, nem mesmo incentivos para contemporânea. (CACCIAMALI, 2001a; CACIAMALI, 2001b; CACCIAMALI, 2000). 
relações de solidariedade social, pertencimento e engajamento. Como no caso anterior, essas contratações sonegam receitas ao Estado, restringindo o fundo público da seguridade social, limitando a implementação de políticas públicas, ou seja, novamente, não contribuem para a interiorização das diferentes dimensões do conceito de cidadania. Por outro lado, o setor empresarial exerce seu poder assimétrico no mercado de trabalho, um ambiente com excesso de mão-de-obra, especialmente, não qualificada, contratando empregados sem registro que implicam menor custo do trabalho, muitas vezes aplicando jornadas excessivas de trabalho e condições degradantes de trabalho.

Os pequenos produtores, membros do setor informal, operam na maioria das vezes sem registro ou licenças, não atendendo a inúmeras regulamentações. Esse comportamento encontrase associado aos processos históricos de exclusão, nos quais os mais pobres vêm sendo submetidos, conforme sondado em muitos países latino-americanos, tais como o Brasil, o México e os países andinos, entre outros. Também observamos processos mais recentes de exclusão, em virtude da persistência de crises políticas e econômicas, como no caso da Argentina, do Uruguai e do Chile. Nesse sentido, a constituição jurídica das atividades informais deve ser contextualizada e analisada por representar um importante instrumento para o exercício da cidadania plena, considerando os processos de objetivação, interiorização e exteriorização. (MOSCOVICI, 1973).

O elevado número de contratações de mão-de-obra sem registro, observado na América Latina nesta década (GALIN, 1998), bem como a expansão de formas de contratação que implícita ou explicitamente burlam a legislação trabalhista (CACCIAMALI, 1999:9-10) e o crescimento das ocupações típicas do setor informal (pequenos produtores e trabalhadores por conta própria) representam, muitas vezes, usos indiscriminados do trabalho (trabalho infantil) e práticas predatórias (horas extensas, baixos salários, entre outros). Todas estas problemáticas acarretam danos à saúde do trabalhador, limitam seu potencial de mobilidade ocupacional e, sobretudo, restringem o sistema de seguridade social (saúde e previdência). A permissividade dos poderes públicos e da própria sociedade quanto a esses procedimentos incidem direta e negativamente sobre a construção e prática da cidadania. 
Para tanto, é importante que haja a construção de um espaço público onde os indivíduos transformem-se em cidadãos que, cumprindo suas obrigações, possam ter acesso aos bens coletivos dos quais têm direito, como reivindicar pelas outras necessidades e, ainda, influenciar no desenho institucional e no uso do dinheiro público, em favor de seu atendimento.

No caso brasileiro, por exemplo, a maior parte da população não percebe os benefícios do uso do dinheiro público, derivados dos impostos e aplicados em bens sociais, nem tem a percepção, presente ou futura, do seu efeito sobre a melhoria da qualidade de vida e na sua vida material. O dinheiro dos impostos é visto como uma ação predatória por parte dos detentores do poder no âmbito do Estado, destinado a interesses privados e às práticas de corrupção, entre outros. Em grandes metrópoles latino-americanas, por outro lado, a ausência de poder público em determinados territórios, desencadeia a apropriação indevida por grupos, muitas vezes ilícita, como: os traficantes de drogas, os contraventores, dentre outros, que procuram preencher tal lacuna. Então exercem, por exemplo, funções de polícia e de justiça, cobram taxas e praticam a assistência social, às vezes, inclusive, associados com membros do próprio poder público.

Essa exclusão, concreta em grande parte, mas também imaginária, em virtude da cultura e da ausência de informações nos estratos populares, faz-se sentir tanto com relação ao acesso à infra-estrutura física, como saneamento e transportes urbanos, por exemplo; quanto nos equipamentos sociais, como, educação, saúde, lazer e cultura; ou na seguridade social, nas aposentadorias, auxílios saúde e maternidade ou seguro desemprego; e até mesmo nos programas públicos destinados, em tese, à população mais carente.

A maioria dos produtores informais desconhece o PROGER (Programa de Geração de Emprego e Renda); ou as ações do Ministério e das Secretarias do Trabalho - PEQ (Plano Estadual de Qualificação); SINE (Sistema Nacional de Emprego); ignoram até mesmo a existência dos programas mais conhecidos, tais como SEBRAE; SENAI; SENAC, assim como ONG's de diferentes natureza (RODRIGUES et al., 1998; CACCIAMALI et al., 1999). Ademais, forte é a crença de que a regularização de suas atividades seja quanto ao uso do espaço público (no caso do comércio de rua, ambulantes ou negócios na periferia) ou à 
aprovação de licenças podem ser mediadas através de relações pessoais especialmente de pessoas influentes (a figura do “pistolão”). (VALARELLI, 1997; SENA, 1998).

A legalização das atividades pode ser ainda coibida pelos custos - financeiros e trâmites burocráticos - e pela desinformação. Em estudo sobre Lima, Peru, há apontamentos de que, nas microempresas que envolvem de 2 a 4 trabalhadores, apenas 35\% poderia cumprir com todas as exigências legais, caso despendessem a totalidade de suas margens brutas de lucro. (CHAVEZ, 1997).

A maioria dos negócios do setor informal é conduzida pelo proprietário, em geral, também chefe da família, com auxílio de mão-de-obra familiar, foram estabelecidos com recursos próprios (poupança, indenizações trabalhistas, entre outros), prescindindo de crédito público ou pessoal que, no caso brasileiro, não é visto como uma restrição para o desenvolvimento do negócio (F.IBGE, 1993). A operacionalização das políticas de microcrédito, muitas vezes, sequer foi desenhada com o objetivo precípuo de contemplar as necessidades e as realidades social e patrimonial do pequeno produtor. Assim, quando a natureza da atividade permite, o negócio é estabelecido na própria residência.

A prática do trabalho é individual, poucas são as filiações a sindicatos, órgãos de classe ou cooperativas. A maioria dos produtores demonstrou algum grau de espírito empreendedor (motivos pessoais, não ser empregado de ninguém, ganhar mais, dentre outros), embora uma parte expressiva tivesse optado por um negócio próprio por ter sido demitido ou por não ter tido acesso a um emprego assalariado. A atividade, em geral, é contínua e regular e, superando um período inicial de até 03 anos, pode tornar-se duradoura.

Grande parte dos produtores do setor informal pouco estudou na escola formal, entretanto uma parcela significativa encontra-se motivada para aumentar seu nível educacional e aprender novas técnicas e qualificações. O que se observa é que, aqueles produtores que se situam no estrato superior de educação e de renda detêm forte motivação e, na maioria das vezes, têm melhores condições objetivas, tanto para assimilar novas técnicas, quanto para desenvolver seus negócios e legalizá-los. 
A maioria das atividades do setor informal encontra-se integrada à produção formal, através da compra de insumos ou de práticas de sub-contratação e a sua demanda por investimentos (máquinas, equipamentos, entre outros) orienta-se para esse setor. Enfim, conforme apontado em estudos dos anos 70 (PREALC, 1978) ou em pesquisas mais recentes, o que se mostra é que os pequenos negócios do setor informal contribuem e incrementam o fluxo geral das transações econômicas, operam em mercados fortemente competitivos e ajustam suas práticas e qualidade dos bens e serviços às mudanças da demanda, de acordo com os gostos e as necessidades de sua clientela, por tratar-se de variável chave para sua sobrevivência.

\section{Informalidade e Cidadania}

As ações do poder público, em seus diferentes níveis, sob os enfoques da sociologia e da economia, são de fundamental importância para o fortalecimento dos pequenos negócios do setor informal, seja para estender a cidadania plena para uma expressiva parte da população, ou para diminuir os custos de transação e ampliar o fluxo geral das atividades econômicas. O potencial empreendedor dos produtores do setor informal e seu senso de oportunidade devem ser reforçados e os entraves à sua legalização devem ser superados por meio da criação de novas práticas e regulamentações.

Destacamos, nestes campos, que ações públicas diferenciadas devem ser implementadas, levando-se em consideração: o ramo de atividade, o tipo de negócio, a rede de relações comerciais com as empresas maiores, bem como a sua localidade. Chamamos a atenção, além disso, para a necessidade de serem implementadas ações específicas para a mão-de-obra, familiar ou não, envolvidas nessas atividades, uma vez que a maioria dos trabalhadores é jovem, possuindo alto potencial para continuar seus estudos ou ingressar em programas de capacitação profissional, entretanto, encontra fortes limitações pela jornada de trabalho longa e diária e pelo baixo salário que lhes é atribuído. Além disso, esses jovens ingressam no mercado de trabalho não observando ou desconhecendo as normas laborais e outras regulamentações vigentes, bem 
como, em geral, não auferem experiência concernentes a um padrão profissional e social adequados, o que virá a dificultar-lhes o acesso a trabalhos de melhor qualidade no futuro.

As ações sobre a cidadania, no entanto, vão e importam além das dimensões citadas acima. Logo, entende-se cidadania como a expressão de um conjunto de direitos que, dentre eles, possibilita aos cidadãos o direito da participação ativa na vida social e nas ações públicas, porém verificamos que o processo de informalidade e o vácuo de ações governamentais restringem e inibem a construção da cidadania. Evidenciamos que esses fenômenos reforçam o descompromisso dos indivíduos com o bem comum e com a prática de ações solidárias, de engajamento e de pertencimento. Entretanto, o processo de informalidade, como contrapartida, também revela novas regras sociais. Poderá, além disso, construir conjuntos de interesses que, uma vez organizados, podem vir a reivindicar novas institucionalidades, visto que:

"democracia e cidadania são processos mediados por instituições, portanto há necessidade de distinguir cidadania passiva, aquela outorgada pelo Estado, de cidadania ativa, aquela que institui o cidadão como portador de direitos e deveres, mas essencialmente criador de direitos para abrir espaços de participação" (CHAUI, 1984: 22).

Reconhecendo que valores de igualdade e de solidariedade não são naturais, mas socialmente determinados e construídos, o desenho dessas novas relações sociais requer uma educação orientada para esses valores. A educação para a paz e para os direitos humanos é uma realidade em vários países da Europa e da América Latina. Esta ação objetiva, primeiramente, uma mudança de mentalidades e considera metodologias que compreendam a interdisciplinaridade, a realidade social, econômica, política e cultural do meio como referencial básico e a compreensão efetiva sobre a integralidade e a indivisibilidade dos direitos fundamentais, seu contexto histórico, seu caráter público e reclamável.

BENEVIDES, analisando as relações entre democracia, educação e cidadania, aponta para a necessidade que se tem de superar a visão liberal e neoliberal, a qual entende: 
“aquela concepção do cidadão como indivíduo livre perante o Estado [o que é essencial], mas visto de forma fragmentada como só o contribuinte, ou só o consumidor definido pelas regras do mercado, ou só eleitor que precisa ser conquistado, ou o trabalhador qualificado que deve ser 'reciclado', ou a elite dirigente mandatária", por direito divino, entre outros. (BENEVIDES, 1998:164).

\section{Considerações Finais}

O mundo contemporâneo está passando por um processo de ruptura histórica, no que diz respeito às suas diferentes dimensões, sejam elas: econômica, política, religiosa, psicológica, cultural, tecnológica, jurídica, territorial, porquanto destacamos estas dentre as principais. Neste contexto, nos encontramos diante de grandes dilemas que, serão solúveis, na medida em que possamos resgatar e/ou construir o real significado de dignidade humana.

Não obstante, o avanço do processo de informalidade coloca em risco a construção da democracia e limita o exercício da cidadania na América Latina. Então, o círculo vicioso, entre mais informalidade e menos cidadania, repousa na convergência das novas dinâmicas, econômicas e políticas, as quais estão estruturando o modelo econômico vigente, bem como sua implementação.

Por outro lado, a vulnerabilidade da estabilidade econômica, seja pelo crescente endividamento interno ou externo dos países ou pela volatilidade dos fluxos de capital especulativo, conduzem a um modo de ajustamento macroeconômico, no qual as restrições ao crescimento econômico e o aumento da competitividade mostram sua contrapartida, principalmente na desorganização e na desregulamentação do mercado de trabalho. Logo, maiores índices de desemprego e subemprego, terceirização sem qualidade e desrespeito à legislação trabalhista são os resultados mais visíveis desse processo. 
O contexto político, caracterizado pela manutenção da concentração do poder político e econômico, gerou forte resistência por parte de empresários e do governo, para priorizar, na agenda política, a discussão dos direitos sociais, sejam eles vinculados à esfera do trabalho ou a outros aspectos da cidadania. Adicionalmente, o movimento sindical ${ }^{6}$ que potencialmente poderia constituir-se numa fonte de ação política, alternativa, também está sustentando seus interesses corporativos de curto prazo, pouco contribuindo para reverter o processo de informalidade ou manter, ou ainda redefinir direitos sociais universais, independentemente da forma de subsunção formal, do indivíduo ter que vender a sua força no mercado de trabalho sob quaisquer formas de inserção laboral (contratos alternativos de trabalho, pequenos negócios, entre outros). Esse último fato agrava-se porque, ao final dos anos de 1990, o trabalho assalariado, típico, passou por mutações e, desde então os trabalhadores registrados representam menos da metade da força de trabalho da região e o número de associados aos sindicatos é relativamente muito pequeno. Dessa maneira, julgamos que essas organizações deveriam conceber esse fato como intrinsecamente pertinente.

A reorganização do movimento sindical torna-se cada vez mais urgente, visto que:

"constitui uma força transformadora de toda a sociedade. Traduz-se em organizações que gradualmente se submetem às regras de uma determinada sociedade, mas é sustentado por fins que transcendem as próprias organizações e que freqüentemente entram em choque com elas. Gera e alimenta o conflito dentro e fora da empresa, mas canaliza a participação social e política de grandes massas, contribuindo para integrá-las na sociedade" (BOBBIO, 1983: p. 1150).

Entretanto, os ambientes econômico e político contemporâneos, intensificam o individualismo e a produção de interesses corporativistas medíocres que restringem as ações

\footnotetext{
${ }^{6}$ Entendemos movimento sindical como "ação coletiva para proteger e melhorar o próprio nível de vida de indivíduos que vendem a sua força de trabalho" (ALLEN, 1968, Apud BOBBIO: p. 1150) e
} 
transformadoras do movimento sindical e limitam o atendimento de novas demandas sociais. Quando, por exemplo, esses interesses se desenvolvem no interior dos poderes públicos, como é o caso do México, ou associado a interesses de governo, como é o caso da Argentina e do Brasil, desta maneira, as contingências para a evolução de novas ações ficam ainda mais restritas.

O quadro apresentado torna-se ainda mais adverso para a construção da cidadania quando constatado que, em muitos países latino-americanos, houve uma desestruturação do poder público ou então, quando se observa sua inoperância. Esse fato obstaculiza tanto a contenção do processo de informalidade quanto a construção de parâmetros de regras sociais e da cidadania, ativa ou passiva. Ao nosso ver, os modelos de Estado, no que se refere à parte da implementação da política social, devem ser redesenhados e engajados para terem condições de responder às necessidades de uma nova realidade e às demandas sociais, novas ou reprimidas, especialmente para superar os processos de exclusão e a primordial questão social de parte substancial da região - a pobreza, sem resvalar em ações unicamente assistenciais.

Nessa perspectiva, uma das alternativas seria a de manter a universalização de direitos sociais, já estabelecidos, tais como: educação, saúde, previdência mínima, além de ampliar outros como o acesso à justiça e a uma atividade remunerada. Seguindo o mesmo ponto de vista, o processo de informalidade, o desemprego e o progressivo aumento de formas de trabalho, alternativas ao assalariamento típico, conduzem para que, em médio prazo, se discutam sobre esses dois últimos temas, sob uma ótica citada, como a que é apresentada pelo Sistema Público de Trabalho e Renda (SPTR) ${ }^{7}$.

\footnotetext{
${ }^{7}$ O Sistema Público de Emprego e Renda conta com recursos do Fundo de Amparo ao Trabalhador (FAT), sendo administrado por um Conselho Tripartite (empresários, trabalhadores e governo). Contra, dentre seus programas e ações, com o seguro-desemprego, informações sobre o mercado de trabalho, intermediação de mão-de-obra, qualificação profissional, microcrédito popular e programas de geração de emprego e renda. Esse conjunto de programas podem ser articulados para apoiar programas de envestimentos em geral, por exemplo, saneamento básico ou habitação, quanto para impulsionar ações de desenvolvimento local.
} 
A defesa de uma proposta como o STPR significa assumir, desde já, a necessidade de se institucionalizar a dimensão social e cívica da cidadania, independentemente do nível de consciência cidadã dos atores sociais, estejam eles sendo representados pelos agentes públicos que controlam os programas assistenciais, pelos empresários que sonegam os impostos, oferecendo empregos sem obedecer às normas legais, além de não pagarem os tributos laborais ou ainda, os próprios indivíduos sofrem a denegação de seus direitos por ignorância ou por incapacidade política de impor sua efetividade.

A prioridade programática dessa proposta, além de representar um processo educativo cívico, amplo e abrangente, compõe o debate presente, pois o SPTR, desde que institucionalizado nos órgãos do Estado, com regras transparentes e com controle social, é um instrumento que pode contribuir de forma decisiva para banir a prática clientelista, as pressões e as demandas corporativistas sobre os sistemas de proteção social e fiscal, cujos fatores comprometem o equilíbrio e a administração das contas públicas. Simultaneamente, por contrapor-se à desestruturação social, decorrente da exacerbação da política neoliberal, corrobora com o desenvolvimento do mercado interno, recompõe a ação do poder público na área social, inserida num contexto contemporâneo de política pública, e pode obstar o surgimento de governos e de ações populistas, conforme verificadas no Peru, há quase dez anos, e na Venezuela, recentemente. O ressurgimento do populismo é uma resposta política, distorcida e manipuladora dos anseios frustrados da maior parte da população que não tem suas necessidades atendidas. Reforçar de forma consistente o Sistema Público de Emprego e Renda SPTR significa responder às aspirações populares de inserção no mercado de trabalho e de acesso à cidadania plena. $\mathrm{O}$ populismo e o assistencialismo não ameaçam apenas a consolidação da democracia nos países latino-americanos, como também reforçam o círculo vicioso entre mais informalidade e menos cidadania, põe em risco a credibilidade política do governo no cenário internacional, infligindo maiores restrições tanto ao crescimento quanto ao desenvolvimento econômico. 


\section{Referências Bibliográficas}

ABREU, S. F. A. Constituição. São Paulo: Global, 1987.

ARENDT, H. Da revolução. São Paulo: Ática, 1988.

BENEVIDES, M.V. O desafio da educação para a cidadania. In: AQUINO, J. G., Diferenças e Preconceito na Escola. Alternativas Teóricas e Práticas. São Paulo: Summus Editorial, 1998.

BOBBIO, A. A era dos direitos. São Paulo: Campus, 1986.

Estado, governo, sociedade. São Paulo: Paz e Terra, 1987.

BOBBIO, A. N.; M. , GIANFRANCO P., Dicionário de política. V.. I e II, Brasília: Editora da UnB - Universidade de Brasília, $11^{\text {a }}$ ed., 1998.

BRUBAKER, W. R. (org.), Imigration and the politics of citizenship in Europe and North America. Lanham, NY e Londres: University Press of America, 1989.

CACCIAMALI, M.C. Processo de Informalidade, flexibilização das relações de trabalho e proteção social na América Latina. Cadernos PUC Economia, n.11, 2001.

. Mudança na natureza da política pública e do mercado de trabalho na América Latina. In: KON, A.; BANKO, C.; MELCHER, D.; CACCIAMALI, M.C. (Coordas). Costos sociales de las reformas laborales en América Latina. Caracas: PUCSP/USP/UCV, 2000 .

Proceso de informalidad y sector informal. Reexamen de una discusión. Revista Venezuelana de Economía y Ciencias Sociales, v. 6, n.3, 2000, pp. 95-110.

. Expansão do mercado de trabalho não regulamentado e setor informal no Brasil. Estudos econômicos. (número especial), v. 19, 1989.

Globalização, informalidade e mercado de trabalho. WORKSHOP INTERNACIONAL - O setor informal revisitado: novas evidências e perspectivas de 
políticas públicas -, IPEA, Brasília, 9-10 jul. 1997. (Este trabalho foi revisado e atualizado em 1998, está sendo submetido para publicação). (mimeo)

Desgaste da legislação laboral e ajustamento do mercado de trabalho no Brasil nos anos 90. In: POSTHUMA, A. (orga.). Brasil. Abertura e ajuste do mercado de trabalho no Brasil. Políticas para conciliar os desafios do emprego e competitividade, OIT. São Paulo: Editora 34, 1999, pp.207-232.

CACCIAMALI, M.C. et al. Desafios da modernização e setor informal urbano: o caso do Brasil. Documento de Trabajo, n.72, OFICINA INTERNACIONAL DE LA OIT PARA AMERICA LATINA Y CARIBE, Lima - Peru, 1998. 1983.

. O setor informal urbano e as formas de participação na produção. São Paulo: IPE,

CASTEL, R. As metamorfoses da questão social. Uma crônica do salário. São Paulo: Vozes, 1998.

CEPAL - COMISIÓN ECONÓMICA PARA AMÉRICA LATINA Y CARIBE. Panorama social de America Latina. Santiago do Chile - Chile, 1998.

CHAVEZ, E. Los marcos regulatórios y la integración del sector informal urbano al proceso de modernización. WORKSHOP INTERNACIONAL - O Setor Informal Revisitado: Novas Evidências e Perspectivas de Políticas Públicas -, IPEA, Brasília, 9-10 jul. 1997.

CHAUI, M. Cultura e democracia. 3. ed. São Paulo:. Moderna, 1984.

COSTA, M.C.C. Democracia. São Paulo: . Global, 1989.

Fundação IBGE . Economia informal urbana. Relatório da pesquisa piloto. Rio de Janeiro, 1993. (mimeo).

JORGE, A. J. Pesquisa de economia informal urbana. WORKSHOP INTERNACIONAL - $O$ Setor Informal Revisitado: Novas Evidências e Perspectivas de Políticas Públicas -, IPEA, Brasília, 9-10 jul. 1997.

MARSHALL, T. H. Citizenship and social class, Londres, Pluto Press, 1967. Apud BOTTOMORE, T. Cidadania, classe e status. Rio de Janeiro, Zahar, 1992.

MOSCOVICI, S. L'homme en interaction: machine à repondre ou machine à inférer. In: MOSCOVICI, S. Introduction à la psychologie sociale, v. I, Paris: Lib.Larousse, 1973. 
OIT. $15^{\mathrm{a} \cdot}$ CONFERÊNCIA DE ESTATÍSTICAS DO TRABALHO. Genebra, jan. 1993.

PREALC - Programa Regional de Empleo en América Latina y el Caribe. La política de empleo en America Latina. El Trimestre Economico, v. 41, n.164, 1974.

, Sector informal: funcionamento y politicas. Santiago, 1978.

RODRIGUES, J.R.M. Et al., Dimensão e natureza do setor informal na grande Belém SECRETARIA DO TRABALHO E PROMOÇÃO SOCIAL - Secretaria do Trabalho e Promoção Social/SEBRAE. Belém - Pará, 1998. (mimeo).

FARHAT, S., Dicionário parlamentar e político. São Paulo: Ed. Fundação Peirópolis: Companhia Melhoramentos, 1996.

SENA, A.L.S. Dimensões da informalidade em Belém. Cadernos do NAEA, Belém, UFPa: Universidade Federal do Pará, n. 14, , 1998.

OUTHWAITE, W. et al. Dicionário do pensamento social do século XX. São Paulo: Jorge Zahar editor, 1996.

TELLES. V. Direitos sociais e direitos dos trabalhadores: por uma ética da cidadania. São Paulo: EDUC, 1997.

TOKMAN, V. E. (direção). De la informalidad a la modernidad. Santiago do Chile: OIT, 2001.

. An exploration into the nature of informal-formal sector relationships. World Development. V.6, n.9/10, 1978.

VALARELLI, M. et al. Informalidade e cidadania. WORKSHOP INTERNACIONAL - $O$ setor informal revisitado: novas evidências e perspectivas de políticas públicas. Brasília: IPEA, 9-10 jul. 1997.

VIERA, L. Cidadania e Globalização. Rio de Janeiro: Record, 1997. 